\title{
Estimation of crustal deformation parameters and strain build-up in Northwest Himalaya using GNSS data measurements
}

\author{
Abhishek YADAV ${ }^{1}$ (D), Suresh KANNAUJIYA ${ }^{1, *}$ (D), \\ Prashant Kumar CHAMPATI RAY ${ }^{1}$ (D), Rajeev Kumar YADAV ${ }^{2,3}$ (D), \\ Param Kirti GAUTAM ${ }^{4}$ (D) \\ ${ }^{1}$ Indian Institute of Remote Sensing, Indian Space Research Organization, \\ Dehradun, Uttarakhand-248001, India \\ ${ }^{2}$ Institute of Seismological Research, Gandhinagar, Gujarat-382009, India \\ ${ }^{3}$ CSIR-National Geophysical Research Institute, Hyderabad-500007, India \\ ${ }^{4}$ Wadia Institute of Himalayan Geology, Dehradun, Uttarakhand-248001, India
}

\begin{abstract}
GPS measurements have proved extremely useful in quantifying strain accumulation rate and assessing seismic hazard in a region. Continuous GPS measurements provide estimates of secular motion used to understand the earthquake and other geodynamic processes. GNSS stations extending from the South of India to the Higher Himalayan region have been used to quantify the strain build-up rate in Central India and the Himalayan region to assess the seismic hazard potential in this realm. Velocity solution has been determined after the application of Markov noise estimated from GPS time series data. The recorded GPS data are processed along with the closest International GNSS stations data for estimation of daily basis precise positioning. The baseline method has been used for the estimation of the linear strain rate between the two stations. Whereas the principal strain axes, maximum shear strain, rotation rate, and crustal shortening rate has been calculated through the site velocity using an independent approach; least-square inversion approach-based triangulation method. The strain rate analysis estimated by the triangulation approach exhibits a mean value of extension rate of 26.08 nano-strain/yr towards $\mathrm{N} 131^{\circ}$, the compression rate of -25.38 nano-strain/yr towards $\mathrm{N} 41^{\circ}$, maximum shear strain rate of 51.47 nano-strain/yr, dilation of -37.57 nano-strain/yr and rotation rate of $0.7^{\circ} / \mathrm{Ma}$ towards anti-clockwise. The computed strain rate from the Baseline method and the Triangulation method reports an extensive compression rate that gradually increases from the Indo-Gangetic Plain in South to Higher Himalaya in North. The slip deficit rate between India and Eurasia Plate in Kumaun Garhwal Himalaya has been computed as $18 \pm 1.5 \mathrm{~mm} / \mathrm{yr}$ based on elastic
\end{abstract}

\footnotetext{
${ }^{*}$ corresponding author: e-mail: skannaujiya@gmail.com
} 
dislocation theory. Thus, in this study, present-day surface deformation rate and interseismic strain accumulation rate in the Himalayan region and the Central Indian region have been estimated for seismic hazard analysis using continuous GPS measurements.

Key words: strain accumulation, crustal deformation, GNSS data, Triangulation method, Baseline method

\section{Introduction}

The ongoing convergence between the Indian and Eurasian Plate is the cause of continuous strain energy accumulation in the Himalayan region. This has resulted in high magnitude earthquakes in the past and could continue in the near future (Bilham et al., 2001). The Himalayan region has already hosted various high magnitude earthquakes previously, 1505 Western Nepal earthquake (Mw 8.5), 1833 Nepal earthquake (Mw 7.9); 1905 Kangra earthquake (Mw 7.8); 1934 Nepal earthquake (Mw 8.1) (Sapkota et al., 2013; Ambraseys and Doughlas, 2004; Bhattacharya and Kayal, 2005; Bollinger et al., 2014). These events have occurred on the detachment separating the overlying wedge rocks from underthrusting Indian shield rocks. The earthquakes are believed to have led to a rupture of some hundreds of kilometres of the regions (Seeber and Armbruster, 1981; Negi et al., 2017). Nearly $20 \mathrm{~mm} / \mathrm{yr}$ of slip rate between Indian and Eurasian plates is accumulated in the Himalayan region due to the Main Himalayan Thrust movement (MHT) (Allmendinger et al., 2007; Ader et al., 2012; Panda et al., 2018).

Main Central Thrust (MCT) is a ductile shear zone that separates the high-grade Greater Himalayan crystalline complex from the low-grade unmetamorphosed Lesser Himalayan sequence. The Main Boundary Thrust (MBT) is a major north- dipping thrust fault overlain by Lesser Himalayan rocks. It affected the upper crust of the Indian Plate during the Cenozoic shortening and formed the present-day structural and orographic boundary between the Outer and Lesser Himalayas. The Main Frontal Thrust (MFT) lies at the Himalaya collision zone's southern margin and appears to accommodate $50-100 \%$ of the shortening across the Himalaya (DeCelles et al., 2001; Lavé et al., 2005). It is the youngest major structural discontinuity, parallel to Himalayan ranges that separate the outermost Siwalik sub-Himalaya from the Indo-Gangetic plains. 
Survey through the use of the Global Navigation Satellite System (GNSS) is a reliable technique for estimating and observing the various geophysical phenomena. This method provides us with accuracy in millimetres, which has unfolded a new avenue for computing crustal deformation parameters (Banerjee and Bürgmann, 2002; Hashimoto et al., 2009). In the current scenario, GNSS based study of crustal deformation has been accepted widely all over the world, and several studies are going on for monitoring tectonic movements for understanding earthquake mechanism. The GPS-derived data of short-term and long-term deformation rate provides us with knowledge regarding the process of strain accumulation, which helps gain information about the preparation of future earthquakes (Kumar et al., 2006; Jade et al., 2014; Gautam et al., 2017; Kannaujiya et al., 2021). Both developments of strain and stress could be estimated with the help of continuous GPS measurements. The GPS observations provide exact information about the position, which helps measure the slow build-up of strain over a period. Seismic study of a region and GPS measurements might help us understand the earthquake mechanics, which would lead to a better assessment of seismic hazards in a particular region.

Therefore, this paper aims in unveiling the future seismic jeopardy in Northwest Himalayan region by GNSS measurements, localized strain rate estimation and calculating the prevailing plate convergence rate.

\section{Regional geology and tectonics}

Himalaya is youngest orogenic event with plate movement $\sim 5 \mathrm{~cm} /$ year since $\sim 55 \mathrm{Ma}$ (Bilham et al., 1997). It is $\sim 2500 \mathrm{~km}$ long and $250-300 \mathrm{~km}$ wide and bounded by Nanga Parbhat in northwest, Namcha Barwa in the northeast (Thakur et al., 2019). The major thrust sheets present here are; South Tibetan Detachment (STD), Main Central Thrust (MCT), Main Boundary Thrust (MBT) and Main Frontal Thrust (MFT) (north to south). The Himalaya is bisected into Trans-Himalaya, the Indus-Tsangpo Suture Zone (ITSZ), the Tethyan Himalaya, the Higher Himalaya, the Lesser Himalaya, and the Sub-Himalaya (Gansser, 1964) from north to south. The geology of the area is composed of granitic and volcanic rocks, greenschist rocks, and deep-sea sediments, sandstone, shale, limestone, quartzite, gneiss, schist, phyllite, slate, and marble. 
The Kumaun-Garhwal Himalaya lies in east of Northwest Himalaya where Munsiari Thrust restricts the Lesser Himalaya and its roots are held by Vaikrita Thrust (Fig. 1). The major klippe structures are: Lansdown-Banoli-Satengal klippen, Ramgarh-Almora klippen and Askot-Baijnath-Pirola klippen. Some tear faults with NE-SW to NNW-SSE orientation are present here which are Ramnagar fault, Tanakpur fault, Raintoli fault, Chaukhutia fault, Bhikiasen fault, Dugadda fault, Nandprayag fault, Nalupani fault, Arakot fault etc.

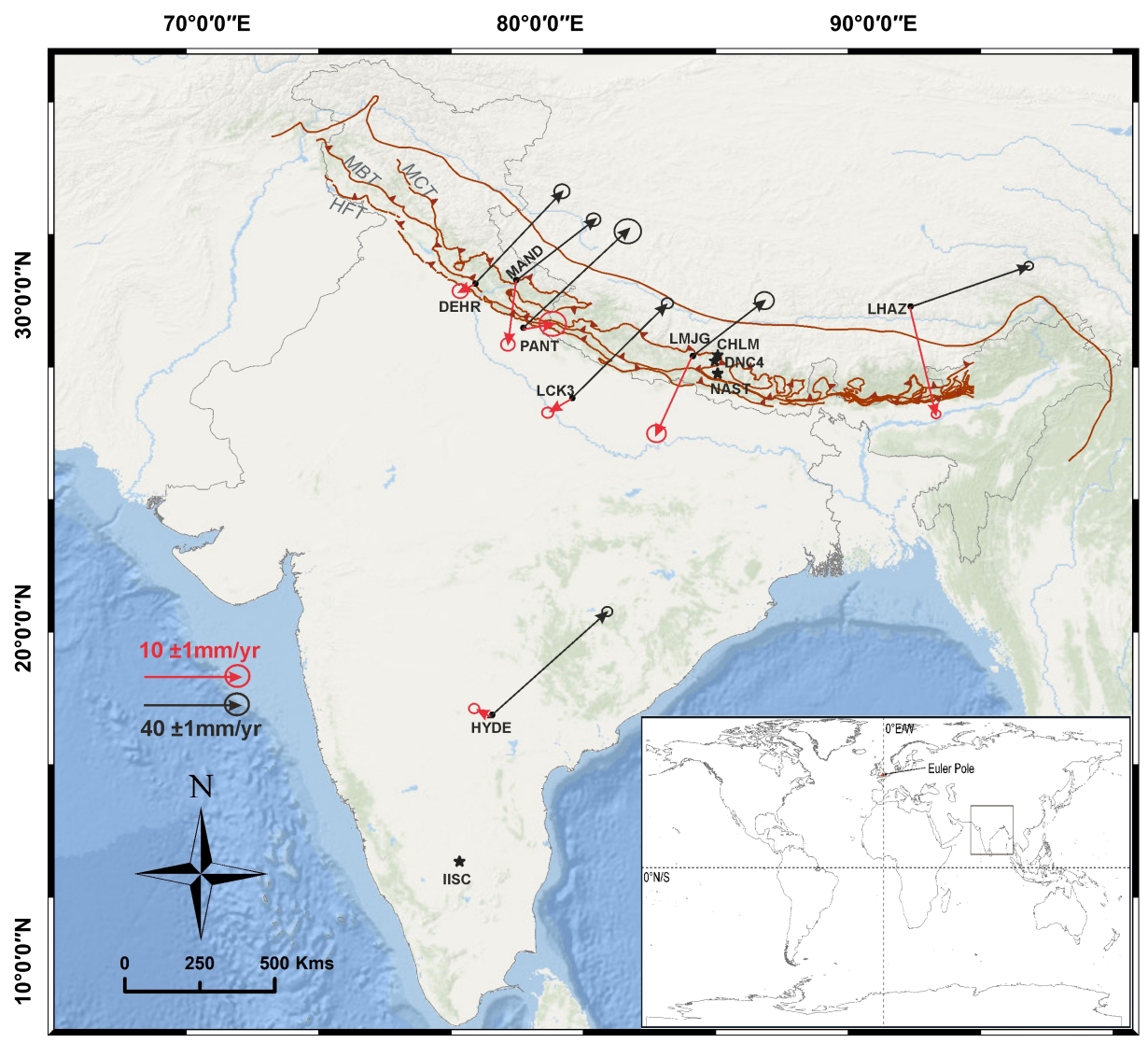

Fig. 1. Sites shown by triangle denotes the GNSS stations used for estimating 2D strain while sites shown with star denotes the stations additionally used for estimating linear strain by applying baseline method. Map showing site velocities where black arrow represents velocity in ITRF 2014 reference frame and red arrow shows velocity in fixed India reference frame. 


\section{Methodology}

\subsection{Estimation of velocity using GPS data}

The ongoing seismic deformation in the Himalayan region is estimated by measuring the interseismic strain accumulated for an extended time. GNSS data obtained from an organized network of GNSS stations can capture the crustal deformation due to slip at active buried sub-surface faults. Considering this, we have used eleven GNSS stations for this study. Three are CORS (Continuously Operating Reference Stations) sites (PANT, DEHR, MAND) installed by IIRS/NRSC-ISRO in Uttarakhand and located in NorthernIndo Gangetic Plain, Outer Himalaya and Higher Himalaya respectively. The remaining eight are the IGS (International GNSS Service) stations (LHAZ, CHLM, DNC4, LMJG, NAST, LCK3, HYDE, IISC) for perceiving a broad picture of the strain accumulated in the Himalayan and Central Indian region.

We have processed the GPS data acquired from these eleven stations (mentioned above) using GAMIT/GLOBK version 10.7 post-processing software (Herring et al., 2010). Core IGS sites were stabilized for estimating the site position and their velocities in International Terrestrial Reference Frame 2008 (ITRF2008) (Altamimi et al., 2011). GAMIT modules have been utilized for estimating the relative positioning of each station with respect to the satellites using accurate details of orbital parameters and errors induced by the ocean-tidal effect, atmospheric water vapour and ionospheric electron content. Further, the site motion estimated from ITRF08 is converted in ITRF14 via the HTDP software (https://geodesy . noaa.gov/TOOLS/Htdp /Htdp.shtml). We have utilized Global Mapping Function (GMF) and temperature from the Global Pressure Temperature (GPT) model to correct the tropospheric delay caused due to dry and wet water mass (Boehm et al., 2007). Finite Element Solution (FES) 2012 and International Earth Rotation System (IERS) 2010 correction model is applied respectively to reduce the ocean tidal and earth tidal loading effect. The final step involves using GLOBK modules to estimate the site velocity in reference to ITRF14 (Altamimi et al., 2011). The velocity solution obtained with respect to ITRF14 indicates that there is secular plate motion towards the northeast, whereas the velocity varies between $39.90 \pm 0.98 \mathrm{~mm} / \mathrm{yr}$ (LMJG) and $53.73 \pm 0.5 \mathrm{~mm} / \mathrm{yr}$ (HYDE). The Indian fixed reference frame velocity 
has been estimated by considering the Indian plate rotation pole (Ader et al., 2012). In the Indian fixed reference frame, these sites move at the rate varying from $1.65 \pm 0.77$ (DEHR) to $22.62 \pm 0.23 \mathrm{~mm} / \mathrm{yr}$ (LHAZ). All the stations show motion predominantly towards Southwest (Fig. 1, Table 1). The considerable variation in the velocity shows that deformation in the plate boundary has occurred due to the underthrusting of the Indian Plate beneath the Eurasian Plate.

Table 1. GNSS derived velocities with respect to ITRF 2014 and fixed India reference frame.

\begin{tabular}{|c|c|c|c|c|c|c|c|c|c|c|c|}
\hline \multirow{2}{*}{ 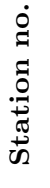 } & \multirow[b]{2}{*}{ 泀 } & \multirow[b]{2}{*}{ 葋 } & \multirow{2}{*}{ 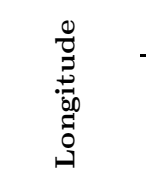 } & \multicolumn{4}{|c|}{ ITRF 2008} & \multicolumn{2}{|c|}{ ITRF 2014} & \multicolumn{2}{|c|}{ FIXED INDIA } \\
\hline & & & & 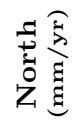 & $\mathrm{Z}_{\mathrm{b}} \stackrel{\widehat{\mathrm{f}}}{\stackrel{\mathrm{g}}{\mathrm{g}}}$ & 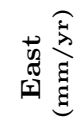 & 됭 ह્ ह્ & 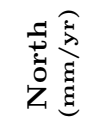 & 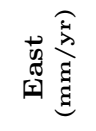 & 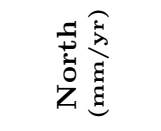 & 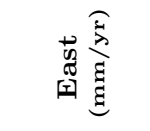 \\
\hline 1 & DEHR & 30.34108 & 78.046548 & 34.16 & 0.52 & 32.4 & 0.58 & 34.25 & 32.4 & -0.7392 & -1.47697 \\
\hline 2 & HYDE & 17.41726 & 78.550874 & 35.82 & 0.44 & 40.06 & 0.26 & 35.92 & 40.06 & 0.781584 & $1-1.47395$ \\
\hline 3 & LCK3 & 26.91218 & 80.955636 & 34.3 & 0.41 & 34.61 & 0.47 & 34.39 & 34.6 & -1.33715 & -2.26885 \\
\hline 4 & LHAZ & 29.65733 & 91.104031 & 15.49 & 0.17 & 43.75 & 0.5 & 15.58 & 44.5 & -21.9868 & 5.330549 \\
\hline 5 & LMJG & 28.17412 & 84.573414 & 24.3 & 0.52 & 31.65 & 0.84 & 24.39 & 31.65 & -12.1244 & -5.54545 \\
\hline 6 & MAND & 30.45296 & 79.272491 & 25.56 & 0.42 & 32.97 & 0.54 & 25.65 & 32.97 & -9.66063 & -1.2133 \\
\hline 7 & PANT & 29.01656 & 79.483671 & 35.83 & 1.25 & 38.34 & 1.41 & 35.92 & 38.34 & 0.555018 & 3.174966 \\
\hline
\end{tabular}

\subsection{Linear strain rate estimation}

The baseline method is useful for the estimation of linear strain between two stations. For calculating linear strain, firstly, it is needed to estimate the baseline length between the two selected stations and for calculation of baseline length, we use the Haversine formula (Tseng and Chang, 2014), which is as follows:

$\alpha=\sin ^{2}(\Delta \varphi / 2)+\cos \varphi_{1} \times \cos \varphi_{2} \times \sin ^{2}(\Delta \lambda / 2)$,

where $\varphi=$ latitude, $\lambda=$ longitude, Earth's radius $(6371 \mathrm{~km})$.

Once we got the baseline length by using the above equation, we can calculate the linear strain by applying the following equation:

$\varepsilon=\left(L_{1}-L_{2}\right) / L_{2}$, 
where $L_{1}=$ initial baseline length, $L_{2}=$ final baseline length.

In this study, for estimation of linear strain, one station needs to be fixed, and then strain is calculated with regard to that fixed station. In this study, we have used LCK3 and IISC as the base stations (fixed) to estimate linear strain (Fig. 2, Tables S1 and S2 in Appendix). To estimate the baseline length, the stations' coordinates are required in the decimal form, which provides us with the baseline length after putting them to the Haversine formula. The baseline length has been calculated for every station at the interval of one year in which the baseline length of the previous year is taken as the initial length $\left(L_{1}\right)$. In contrast, the following year's baseline length is taken as the final length $\left(L_{2}\right)$.
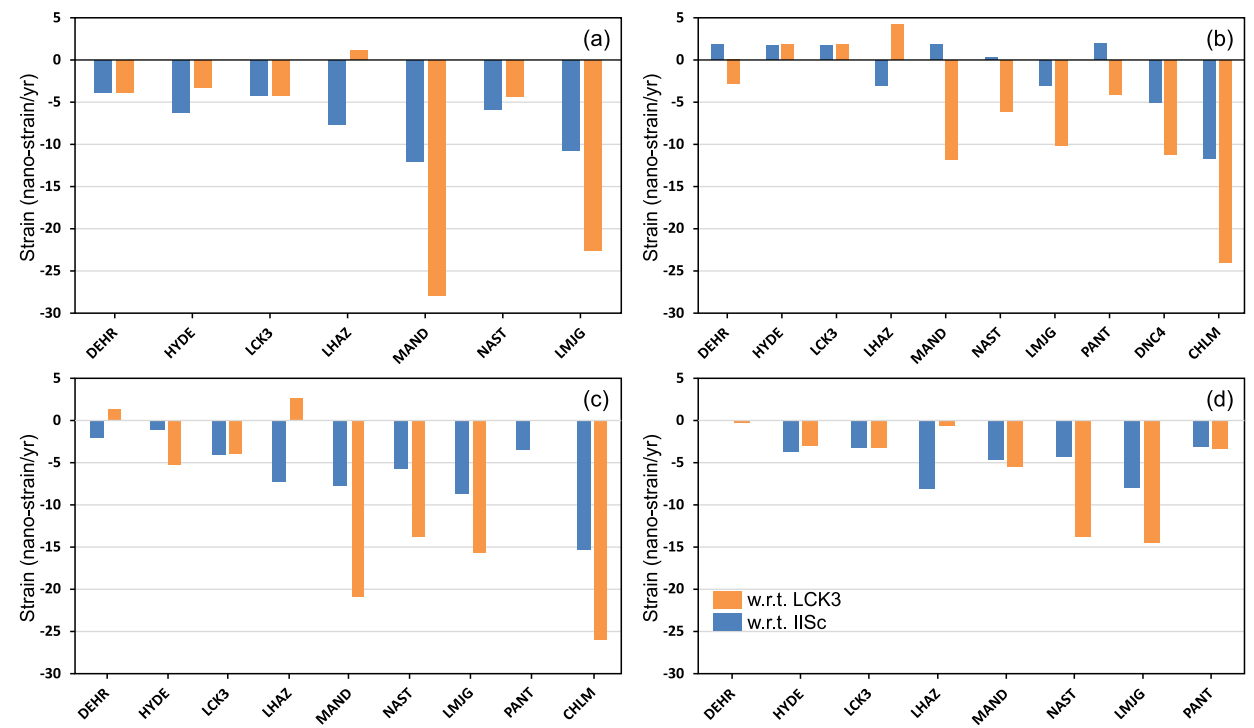

Fig. 2. Linear strain estimated from the year 2014 to 2019 while keeping LCK3 and IISc as fixed stations (a)-(d). Here, orange bar represents strain rate estimation with respect to LCK3 GNSS station whereas the blue bar represents strain rate estimation with respect to IISc GNSS station.

\subsection{Strain rate estimation on localized scale}

The analysis of Triangulation method emerged when the method of measuring the angle by atmosphere of Earth became restricted, in respect to its precision unit by 1 second of the arc as there was fluctuation in the refrac- 
tive index of air repeatedly. To delineate localized two-dimensional crustal strain in our study area (Fig. 3, Table S3 in Appendix) we have used the triangulation method (Bibby, 1975). In this method, the velocities of three nonlinear GPS sites are utilized to estimate several crustal deformation parameters at the centroid of the triangle formed. Further, Cronin et al. (2012) developed the software package for measuring the translational vector, principle strain, maximum shear, rotation and areal strain. The deformation rate expressed in four terms $\left(\varepsilon_{x x}, \varepsilon_{x y}, \varepsilon_{y x}, \varepsilon_{y y}\right)$ and the translation motion $\left(t_{x}, t_{y}\right)$ are used for describing each component of the horizontal velocity. Below are the equations used for estimating crustal deformation parameters:

speed $=\sqrt{t_{x}^{2}+t_{y}^{2}}$,
rotation $(w)=\left(\begin{array}{cc}0 & \frac{\varepsilon_{x y}-\varepsilon_{y x}}{2} \\ \frac{\varepsilon_{y x}-\varepsilon_{x y}}{2} & 0\end{array}\right)$,

2D Lagrangian strain rate $\left(\varepsilon_{i j}\right)=\left(\begin{array}{ll}\varepsilon_{x x} & \varepsilon_{x y} \\ \varepsilon_{y x} & \varepsilon_{y y}\end{array}\right)$,

maximum shear strain $\left(Y_{\max }\right)=\sqrt{\left(\frac{\varepsilon_{x x}-\varepsilon_{y y}}{2}\right)+\left(\varepsilon_{x y}\right)^{2}}$.

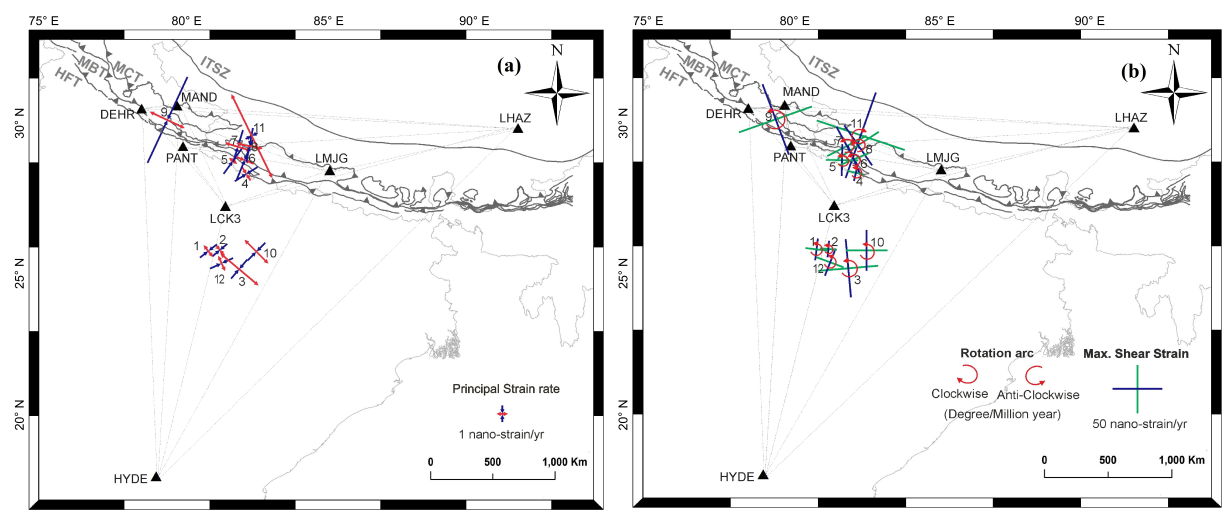

Fig. 3. Strain estimated using triangulation method; Maximum shear strain rate and rotation axis estimated from site velocity (a). Strain estimated using triangulation method; Horizontal principal strain axes derived from GPS measure (b). 


\subsection{Estimation of prevailing convergence rate}

The plate convergence rate in Kumaun Garhwal Himalaya between India and Eurasia plate has been estimated using both three CORS/GNSS stations from (mentioned before) and stations data from already published work (Yadav et al., 2019). Previous studies indicate that the current convergence is occurring along the Main Himalayan Thrust (Thakur, 2013), and hence MFT is the active thrust belt in Himalaya. It also says that the strike of MFT in the Kumaun Garhwal Himalaya is nearly $303^{\circ}$. The velocity estimates obtained in the ITRF reference frame is converted to India fixed frame, which is then decomposed into fault perpendicular (normal to strike direction) and fault parallel (along the strike direction) components. Here, the fault parallel velocity is considered strike-slip while fault normal velocity is taken as dip-slip on Main Himalayan Thrust (MHT).

We have utilized grid search technique to minimize the misfit between the calculated and observed site velocity for estimation of width of the frontal locked portion of MHT, the dip angle of MHT and crustal shortening rate based on elastic dislocation theory. Iterations have been performed over the parameters such as the width of locked portion, dip angle, locking depth and slip rate (Fig. 4).

\section{Results}

\subsection{Inference from linear strain rate estimation}

To understand the crustal deformation in the Himalayan region and other parts of India, IGS sites LCK3 and IISc situated in Lucknow and Bangalore, respectively, were used as a reference to estimate the linear or 1D strain accumulation. This study has been done using GPS data from the year 2014 to 2019. The strain accumulation with respect to LCK3 fixed station, infers that during the year 2014-2015, MAND shows the maximum amount of linear strain accumulation with the rate of -50.4212 nano-strain/year, followed by LHAZ having a rate of 35.6854 nano-strain/year. The next year, i.e. 2015-2016, again MAND has a maximum strain rate of about -27.9511 nano-strain/yr. CHLM has the highest accumulation of strain rate in 20162017, where the strain rate is -24.0931 nano-strain/yr, and again in the year of 2017-2018, CHLM is showing maximum strain rate of -25.9284 


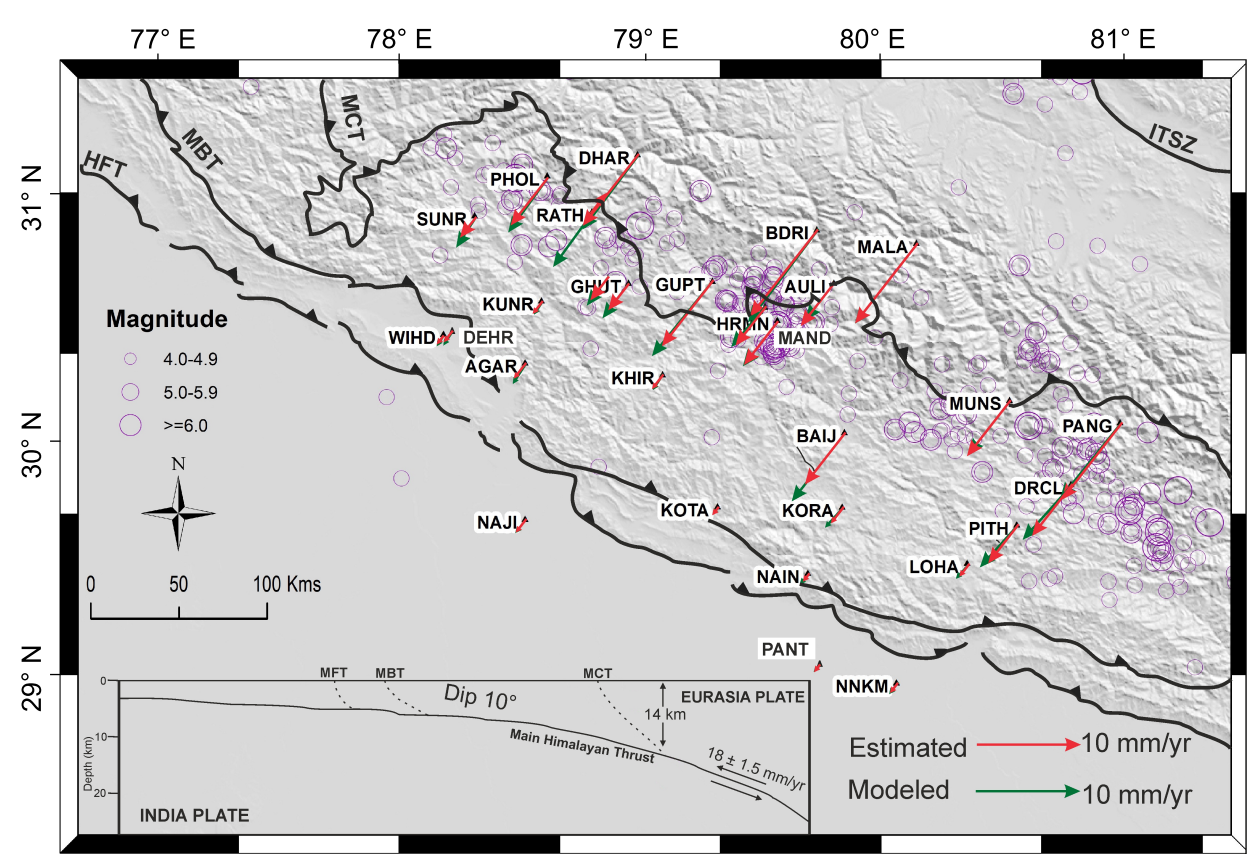

Fig. 4. Comparison of estimated and modelled velocities obtained for estimating the prevailing convergence rate, locked width and uniform dip angle. The violet colour circles represent the seismicity (archived) with varying magnitude.

nano-strain/yr. For the year 2018-2019, MAND shows the highest strain rate of -5.52671 nano-strain/yr (Table S1).

Similarly, linear strain accumulation has been estimated using IISc as the fixed station for the same period. We can observe that for the year 2014-2015, MAND shows the maximum amount of linear strain accumulation with the rate of -13.87104 nano-strain/year, followed by LHAZ having a rate of -9.83649 nano-strain/year. The next year, i.e. 2015-2016, again MAND has a maximum strain rate of about -11.9832 nano-strain/yr. CHLM has the highest accumulation of strain rate in 2016-2017, where the strain rate is -11.7095 nano-strain/yr, and again in the year of 2017-2018, CHLM is showing maximum strain rate of -15.31 nano-strain/yr while for the year 2018-2019, MAND is showing the highest strain rate of which is -4.6146 nano-strain/yr (Table S2). 


\subsection{Inference from Triangulation rate estimation method}

Observing crustal strain perturbation is necessary to know the ongoing processes beneath the earth's crust. And for this purpose, GNSS measurements for an extended period play an important role. We calculated the triangular network's strain rate over a regular grid's nodes taking into consideration three stations. The strain and rotation rates are calculated at the centroid of twelve triangular zones of sites in the cluster, and the estimates are listed in Table S3. The extension rate varies from -8.4824 nano-strain/yr to 173.5316 nano-strain/yr with variation in azimuth from $\mathrm{N} 101^{\circ}$ to $\mathrm{N} 156^{\circ}$, and compression rate ranges between 6.31 nano-strain/yr and -95.3 nanostrain/yr corresponding with azimuth from $\mathrm{N} 11^{\circ}$ to $\mathrm{N} 66^{\circ}$ (Fig. 3). The maximum shear strain rate ranges from 7.41 nano-strain/yr to 172.21 nanostrain/yr towards $45^{\circ}$ of principal strain rate, and areal strain rate varies from -67.46 nano strain/yr to 184.84 nano-strain/yr. The rate of vertical axis rotation ranges between $-1.57^{\circ}$ and $0.71^{\circ} / \mathrm{Ma}$. This strain rate analysis provides the mean value of extension rate of 26.08 nano-strain/yr towards $\mathrm{N} 131^{\circ}$, compression rate of -25.38 nano-strain/yr towards $\mathrm{N} 41^{\circ}$, maximum shear strain rate of 51.47 nano-strain/yr, dilation of -37.57 nano-strain/yr and rotation rate of $0.7^{\circ} / \mathrm{Ma}$ towards anti-clockwise.

\subsection{Inference from ongoing plate convergence rate}

For the estimation of crustal shortening rate, we have utilized the surface velocity measurements. We have assumed MHT as a weak zone of failure, and then by using elastic dislocation theory, the slip rate has been calculated. It could be observed that the velocity field normal to the fault is varying with respect to the distance from MFT. Okada's green function (Okada, 1985) is applied, and it has been considered the frontal portion of MHT is brittle, and up to some extent, it remains locked. While remaining portion aseismically creeps with a uniform slip rate. The estimated plate convergence rate on Eurasia and India plate's fault interface varies from 0 to $18 \mathrm{~mm} / \mathrm{yr}$ with a uniform dip angle $10^{\circ}$ (Fig. 4). From this observation, it can be inferred that the front portion of MHT is locked perfectly (estimated locked depth, $14 \mathrm{~km}$ ), and it creeps steadily further north during the interseismic period. 


\section{Discussions}

An increase in temperature-pressure with depth weakens the coupling activity at the plate interface, thereby becoming the vulnerable spot for active plate convergence, resulting in a high compression rate in the Higher Himalaya. The estimated value of the prevailing plate convergence rate in the Northwest Himalayan region is $18 \pm 1.5 \mathrm{~mm} / \mathrm{yr}$ (Fig. 4). Consequently, in the Lesser or Outer Himalaya, where a low compression rate is observed, it is due to the friction taking place between two plates, thus giving rise to interseismic coupling activity (Yadav et al., 2019). According to some previous researchers, geophysical studies have detected lateral heterogeneity (vary the recurrence interval and intensity of seismic activity of high magnitude) and asperity zones in the Northwest Himalayan region. These asperity zones are identified as a zone of anomaly that considerably dismayed the crustal deformation (Srivastava and Mitra et al., 1994; Ponraj et al., 2011; Yadav et al., 2017; Dal Zilio et al., 2020). A long-duration seismic catalogue shows shallow depth seismic deformation at Higher Himalaya, while the lateral change in seismicity rate infers probable variability in MHT locking width. Along with it, seismic imaging of the Northwest Himalaya infers the presence of a ramp structure of MHT thrust fault which is located beneath the Higher Himalaya. Thus, strain budget estimation conveys that, although quite a significant amount of elastic strain energy has accumulated since the occurrence of past major earthquakes, but only a tiny amount of it is released. This validates the fact that the Kumaun-Garhwal region of Northwest Himalaya is capable of an high magnitude earthquake event in the near future.

\section{Conclusion}

Here we have tried to observe the crustal deformation in the Himalaya and the central India region to analyse the strain accumulation in these regions due to the tectonic activity. We have used two methods for estimating strain rate, i.e. baseline method for calculation of linear strain and segmentation method for using the triangular network (using eleven GNSS stations). Using the baseline method, we estimated linear strain, which shows that, with respect to LCK3 and IISc, most of the GNSS stations lying in the Himalayan 
region show compressional regime due to the northward movement of the Indian Plate and its thrusting beneath the Eurasian Plate. The highest amount of linear strain accumulation can be seen at CHLM and MAND, which could be attributed to their location close to MCT compared to other stations. Simultaneously, the triangulation method helped estimate maximum shear strain, principal strain axis, dilation, and rotation rate. The estimated plate convergence rate (where we have used published stations data along with the eleven GNSS stations data) is about $18 \mathrm{~mm} / \mathrm{yr}$, estimated locked depth is $14 \mathrm{~km}$ and with a uniform dip angle of $10^{\circ}$ in the study realm (Kumaun-Garhwal Himalaya region). We can finally infer that there is further need to carry out $2 \mathrm{D}$ analysis with large datasets to improve our knowledge and understanding of the ongoing convergence between Indian and Eurasian plates. The strain budget analysis based on estimated present-day convergence rate in the region indicates the potentiality of an high magnitude earthquake event in the future.

Acknowledgements. We express our gratitude to the Chairman, ISRO, for sponsoring this research work. The authors also acknowledge the Directors of the Indian Institute of Remote Sensing, Wadia Institute of Himalayan Geology, Dehradun to accomplish this study. We also acknowledge NRSC, Hyderabad and UNAVCO for providing their data, which helped us carry out the research work effortlessly. We also acknowledge those scholars who have diligently assisted us in data collection and processing. The authors are thankful to Dr. Robert W. King (MIT) for providing GAMIT/GLOBK 10.70 software for processing GPS data. This is NGRI publication number NGRI/Lib/2021/Pub120. On a special note, the authors dedicate this work in honour of late Dr. Champati ray, whom we lost amidst the COVID-19 second wave because the research initiative on geodynamics was taken up by him. The authors also acknowledge the Editor-in Chief and the anonymous reviewer for giving such wonderful suggestions.

\section{References}

Ader T., Avouac J.-P., Liu-Zeng J., Lyon-Caen H., Bollinger L., Galetzka J., Genrich J., Thomas M., Chanard K., Sapkota S. N., Rajaure, S., Shrestha P., Ding L., Flouzat M., 2012: Convergence rate across the Nepal Himalaya and interseismic coupling on the Main Himalayan Thrust: Implications for seismic hazard. J. Geophys. Res. Solid Earth, 117, B4, B04403, doi: 10.1029/2011JB009071.

Allmendinger R. W., Reilinger R., Loveless J., 2007: Strain and rotation rate from GPS in Tibet, Anatolia, and the Altiplano. Tectonics, 26, 3, TC3013, doi: 10.1029/2006 TC002030. 
Altamimi Z., Collilieux X., Métivier L., 2011: ITRF2008: an improved solution of the international terrestrial reference frame. J. Geod., 85, 8, 457-473, doi: 10.1007/s00 190-011-0444-4.

Ambraseys N. N., Douglas J., 2004: Magnitude calibration of north Indian earthquakes. Geophys. J. Int., 159, 1, 165-206, doi: 10.1111/j.1365-246X.2004.02323.x.

Banerjee P., Bürgmann R., 2002: Convergence across the northwest Himalaya from GPS measurements. Geophys. Res. Lett., 29, 13, 30-1-30-4, doi : 10.1029/2002GL015184.

Bhattacharya S. N., Kayal J. R., 2005: Seismicity of the Himachal Himalaya: constraint from local seismic network. Geol. Surv. India, Spec. Publ., 85, 71-79.

Bibby H. M., 1975: Crustal strain from triangulation in Marlborough, New Zealand. Tectonophysics, 29, 1-4, 529-540, doi: 10.1016/0040-1951(75)90180-8.

Bilham R., Gaur V. K., Molnar P., 2001: Himalayan seismic hazard. Science, 293, 5534, 1442-1444, doi: 10.1126/science.1062584.

Bilham R., Larson K., Freymueller, J., 1997: GPS measurements of present-day convergence across the Nepal Himalaya. Nature, 386, 6620, 61-64, doi: 10. 1038/386061a0.

Boehm J., Heinkelmann R., Schuh H., 2007: Short note: a global model of pressure and temperature for geodetic applications. J. Geod., 81, 10, 679-683, doi: 10.1007/s00 190-007-0135-3.

Bollinger L., Sapkota S. N., Tapponnier P., Klinger Y., Rizza M., Van der Woerd J., Tiwari D. R., Pandey R., Bitri A., Bes de Berc S., 2014: Estimating the return times of great Himalayan earthquakes in eastern Nepal: Evidence from the Patu and Bardibas strands of the Main Frontal Thrust. J. Geophys. Res. Solid Earth, 119, 9, 7123-7163, doi : 10.1002/2014JB010970.

Cronin V. S., Resor P. G., Hammond W. C., Kreemer C. W., Olds S. E., Pratt-Sitaula B., West N. W., 2012: Developing a curricular module for introductory geophysics or structural geology courses to quantify crustal strain using EarthScope PBO GPS velocities. In: AGU Fall Meeting Abstracts, 2012, ED41B-0681.

Dal Zilio L., Jolivet R., van Dinther Y., 2020: Segmentation of the Main Himalayan Thrust Illuminated by Bayesian Inference of Interseismic Coupling. Geophys. Res. Lett., 47, 4, doi : 10.1029/2019GL086424.

DeCelles P. G., Robinson D. M., Quade J., Ojha T. P., Garzione C. N., Copeland P., Upreti B. N., 2001: Stratigraphy, structure, and tectonic evolution of the Himalayan fold-thrust belt in western Nepal. Tectonics, 20, 4, 487-509, doi: 10.1029/2000TC 001226.

Gansser A., 1964: Geology of the Himalayas. Interscience Publishers, London, New York, Sydney, 289 p.

Gautam P. K., Gahalaut V. K., Prajapati S. K., Kumar N., Yadav R. K., Rana N., Dabral C. P., 2017: Continuous GPS measurements of crustal deformation in GarhwalKumaun Himalaya. Quat. Int., 462, 124-129, doi : 10.1016/j .quaint.2017.05.043.

Hashimoto C., Noda A., Sagiya T., Matsu'ura M., 2009: Interplate seismogenic zones along the Kuril-Japan trench inferred from GPS data inversion. Nat. Geosci., 2, 2, 141-144, doi : 10.1038/ngeo421. 
Herring T. A., King R. W., McClusky, S. C., 2010: Introduction to Gamit/Globk. Release 10.4. Massachusetts Institute of Technology, Cambridge, Massachusetts, 48 p.

Jade S., Mukul M., Gaur V. K., Kumar K., Shrungeshwar T. S., Satyal G. S., Dumka R. K., Jagannathan S., Ananda M. B., Kumar P. D., Banerjee S., 2014: Contemporary deformation in the Kashmir-Himachal, Garhwal and Kumaon Himalaya: significant insights from 1995-2008 GPS time series. J. Geod., 88, 6, 539-557, doi : $10.1007 / \mathrm{s} 00190-014-0702-3$.

Kannaujiya S., Gautam P. K., Champati ray P. K., Chauhan P., Roy P. N. S., Pal S. K., Taloor A. K., 2021: Contribution of seasonal hydrological loading in the variation of seismicity and geodetic deformation in Garhwal region of Northwest Himalaya. Quat. Int., 575-576, 62-71, doi: 10.1016/j .quaint.2020.04.049.

Kumar S., Wesnousky S. G., Rockwell T. K., Briggs R. W., Thakur V. C., Jayangondaperumal R., 2006: Paleoseismic evidence of great surface rupture earthquakes along the Indian Himalaya. J. Geophys. Res. Solid Earth, 111, B3, B03304, doi: 10.1029/20 04JB003309.

Lavé J., Yule D., Sapkota S., Basant K., Madden C., Attal M., Pandey R., 2005: Evidence for a great medieval earthquake ( ${ }^{1100}$ A.D.) in the central Himalayas, Nepal. Science, 307, 5713, 1302-1305, doi: 10.1126/science.1104804.

Negi S. S., Paul A., Cesca S., Kamal, Kriegerowski M., Mahesh P., Gupta S., 2017: Crustal velocity structure and earthquake processes of Garhwal-Kumaun Himalaya: Constraints from regional waveform inversion and array beam modeling. Tectonophysics, 712-713, 45-63, doi: 10.1016/j.tecto.2017.05.007.

Okada Y., 1985: Surface deformation due to shear and tensile faults in a half-space. Bull. Seismol. Soc. Am., 75, 4, 1135-1154, doi : 10.1785/BSSA0750041135.

Panda D., Kundu B., Gahalaut V. K., Bürgmann R., Jha B., Asaithambi R., Yadav R. K., Vissa N. K., Bansal A. K., 2018: Seasonal modulation of deep slow-slip and earthquakes on the Main Himalayan Thrust. Nat. Commun., 9, 4140, doi: 10.1038/s414 67-018-06371-2.

Ponraj M., Miura S., Reddy C. D., Amirtharaj S., Mahajan, S. H., 2011: Slip distribution beneath the Central and Western Himalaya inferred from GPS observations. Geophys. J. Int., 185, 2, 724-736, doi: 10.1111/j.1365-246X.2011.04958.x.

Sapkota S. N., Bollinger L., Klinger Y., Tapponnier P., Gaudemer Y., Tiwari D., 2013: Primary surface ruptures of the great Himalayan earthquakes in 1934 and 1255 . Nat. Geosci., 6, 1, 71-76, doi: 10.1038/ngeo1669.

Seeber L., Armbruster J. G., 1981: Great detachment earthquakes along the Himalayan arc and long-term forecasting. In: Simpson D. W., Richards P. G. (Eds.): Earthquake Prediction: An International Review, Vol. 4, American Geophysical Union, 259-277, doi: 10.1029/ME004p0259.

Srivastava P., Mitra G., 1994: Thrust geometries and deep structure of the outer and lesser Himalaya, Kumaon and Garhwal (India): Implications for evolution of the Himalayan fold-and-thrust belt. Tectonics, 13, 1, 89-109, doi : 10.1029/93TC01130.

Thakur V. C., 2013: Active tectonics of Himalayan frontal fault system. Int. J. Earth Sci., 102, 7, 1791-1810, doi: 10.1007/s00531-013-0891-7. 
Thakur V. C., Jayangondaperumal R., Joevivek V., 2019: Seismotectonics of central and NW Himalaya: plate boundary-wedge thrust earthquakes in thin- and thickskinned tectonic framework. In: Sharma R., Villa I. M., Kumar S. (Eds.): Crustal Architecture and Evolution of the Himalaya-Karakoram-Tibet Orogen. Geological Society, London, Special Publications, 481, 1, 41-63, doi: 10.1144/SP481.8.

Tseng W. K, Chang W. J., 2014: Analogues between 2D linear equations and great circle sailing. J. Navig., 67, 1, 101-112, doi: 10.1017/s0373463313000532.

Yadav R. K., Roy P. N. S., Gupta S. K., Khan P. K., Catherine J. K., Prajapati S. K., Kumar A., Puviarasan N., Bhu H., Devachandra M., Malik J., Kundu B., Debbarma C., Gahalaut V. K., 2017: Rupture model of Mw 7.8 2015 Gorkha, Nepal earthquake: Constraints from GPS measurements of coseismic offsets. J. Asian Earth Sci., 133, 56-61, doi: 10.1016/j.jseaes.2016.04.015.

Yadav R. K., Gahalaut V. K., Kumar A., Sati S. P., Catherine J., Gautam P., Kumar K., Rana N., 2019: Strong seismic coupling underneath Garhwal-Kumaun region, NW Himalaya, India. Earth Planet. Sci. Lett., 506, 8-14, doi: 10.1016/j.epsl.2018. 10.023 .

\section{Appendix}

Supplementary tables:

Table S1. Estimation of Linear strain rate when LCK3 station is kept fixed.

\begin{tabular}{|c|c|c|}
\hline Year & Station & $\begin{array}{c}\text { Strain rate } \\
(\text { nano-strain/yr) }\end{array}$ \\
\hline \multirow{5}{*}{ 2014-2015 } & DEHR & -37.1449 \\
\hline & HYDE & -13.3656 \\
\hline & IISC & -5.1092 \\
\hline & LHAZ & 35.6854 \\
\hline & MAND & -50.4212 \\
\hline \multirow{7}{*}{$2015-2016$} & DEHR & -3.85958 \\
\hline & HYDE & -3.26914 \\
\hline & IISC & -4.20678 \\
\hline & LHAZ & 1.06629 \\
\hline & MAND & -27.9511 \\
\hline & NAST & -4.30992 \\
\hline & LMJG & -22.5568 \\
\hline \multirow{3}{*}{ 2016-2017 } & DEHR & -2.92685 \\
\hline & HYDE & 1.68093 \\
\hline & IISC & 1.6717 \\
\hline
\end{tabular}


Table S1. Continued from the previous page.

\begin{tabular}{|c|c|c|}
\hline Year & Station & $\begin{array}{c}\text { Strain rate } \\
(\text { nano-strain } / \mathbf{y r})\end{array}$ \\
\hline \multirow{7}{*}{ 2016-2017 } & LHAZ & 4.0982 \\
\hline & MAND & -11.8541 \\
\hline & NAST & -6.16694 \\
\hline & LMJG & -10.27 \\
\hline & PANT & -4.21347 \\
\hline & DNC4 & -11.2366 \\
\hline & CHLM & -24.0931 \\
\hline \multirow{9}{*}{$2017-2018$} & DEHR & 1.41708 \\
\hline & HYDE & -5.36092 \\
\hline & IISC & -4.03526 \\
\hline & LHAZ & 2.73959 \\
\hline & MAND & -20.8307 \\
\hline & NAST & -13.7452 \\
\hline & LMJG & -15.7234 \\
\hline & PANT & -0.16971 \\
\hline & CHLM & -25.9284 \\
\hline \multirow{9}{*}{ 2018-2019 } & DEHR & -3.872785 \\
\hline & HYDE & -3.00174 \\
\hline & IISC & -3.22146 \\
\hline & LHAZ & -0.597356 \\
\hline & MAND & -5.52671 \\
\hline & NAST & -1.37378 \\
\hline & LMJG & -1.45028 \\
\hline & PANT & -3.42577 \\
\hline & GNFC & -0.3871 \\
\hline
\end{tabular}

Table S2. Estimation of Linear strain rate when IISc station is kept fixed.

\begin{tabular}{ccc}
\hline Year & Station & $\begin{array}{c}\text { Strain rate } \\
\text { (nano-strain/yr) }\end{array}$ \\
\hline \multirow{3}{*}{$\mathbf{2 0 1 4 - 2 0 1 5}$} & DEHR & 1.44358 \\
\cline { 2 - 3 } & HYDE & 1.25654 \\
\cline { 2 - 3 } & LCK3 & -5.1092 \\
\cline { 2 - 3 } & LHAZ & -9.83649 \\
\cline { 2 - 3 } & MAND & -13.87104 \\
\hline
\end{tabular}


Yadav A. et al.: Estimation of crustal deformation parameters and strain ... (225-243)

Table S2. Continued from the previous page.

\begin{tabular}{|c|c|c|}
\hline Year & Station & $\begin{array}{c}\text { Strain rate } \\
(\text { nano-strain/yr) }\end{array}$ \\
\hline \multirow{7}{*}{ 2015-2016 } & DEHR & -3.88687 \\
\hline & HYDE & -6.21222 \\
\hline & LCK3 & -4.20678 \\
\hline & LHAZ & -7.58042 \\
\hline & MAND & -11.9832 \\
\hline & NAST & -5.81069 \\
\hline & LMJG & -10.6971 \\
\hline \multirow{10}{*}{ 2016-2017 } & DEHR & 1.76846 \\
\hline & HYDE & 1.65513 \\
\hline & LCK3 & 1.6717 \\
\hline & LHAZ & -3.06303 \\
\hline & MAND & 1.70888 \\
\hline & NAST & 0.160146 \\
\hline & LMJG & -3.13124 \\
\hline & PANT & 1.80665 \\
\hline & DNC4 & -5.16386 \\
\hline & CHLM & -11.7095 \\
\hline \multirow{9}{*}{ 2017-2018 } & DEHR & -2.09321 \\
\hline & HYDE & -1.14075 \\
\hline & LCK3 & -4.03526 \\
\hline & LHAZ & -7.26476 \\
\hline & MAND & -7.72798 \\
\hline & NAST & -5.64799 \\
\hline & LMJG & -8.64985 \\
\hline & PANT & -3.42881 \\
\hline & CHLM & -15.31 \\
\hline \multirow{8}{*}{ 2018-2019 } & DEHR & 0.0653812 \\
\hline & HYDE & -3.685 \\
\hline & LCK3 & -3.22146 \\
\hline & LHAZ & -8.09205 \\
\hline & MAND & -4.6146 \\
\hline & NAST & -4.31088 \\
\hline & LMJG & -7.973 \\
\hline & PANT & -3.11949 \\
\hline
\end{tabular}


Table S3. Localized strain rate estimation using the Triangulation method.

\begin{tabular}{|c|c|c|c|c|c|c|c|c|}
\hline 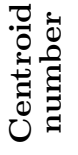 & 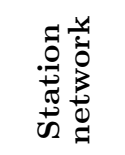 & $\begin{array}{r}\epsilon_{\max } \\
\left(10^{-9}\right)\end{array}$ & Trend & $\begin{array}{r}\boldsymbol{\epsilon}_{\min } \\
\left(10^{-9}\right)\end{array}$ & Trend & $\begin{array}{l}\text { Max } \\
\text { shear } \\
\text { strain } \\
\left(10^{-9}\right)\end{array}$ & $\begin{array}{c}\text { Dilation } \\
\left(10^{-9}\right)\end{array}$ & $\begin{array}{l}\text { Rotation } \\
(\text { degree/yr) }\end{array}$ \\
\hline 1 & $\begin{array}{l}\text { HYDE } \\
\text { LMJG } \\
\text { DEHR }\end{array}$ & 5.7116 & 142.6583 & -13.5285 & 52.6583 & 19.2402 & -7.8169 & -0.00000053 \\
\hline 2 & $\begin{array}{l}\text { HYDE } \\
\text { LMJG } \\
\text { MAND }\end{array}$ & -3.6733 & 140.1648 & -11.0844 & 50.1648 & 7.4112 & -14.7577 & -0.00000025 \\
\hline 3 & $\begin{array}{c}\text { HYDE } \\
\text { LCK3 } \\
\text { LHAZ }\end{array}$ & 52.9705 & 130.3736 & -15.9755 & 40.3736 & 68.9460 & 36.9951 & -0.00000157 \\
\hline 4 & $\begin{array}{c}\text { LCK3 } \\
\text { LMJG } \\
\text { PANT }\end{array}$ & -4.4757 & 148.5504 & -18.8974 & 58.5504 & 14.4217 & -23.3731 & -0.00000118 \\
\hline 5 & $\begin{array}{c}\text { LCK3 } \\
\text { LMJG } \\
\text { DEHR }\end{array}$ & 2.5192 & 126.7931 & -26.1298 & 36.7931 & 28.6490 & -23.6107 & -0.00000058 \\
\hline 6 & $\begin{array}{c}\text { LCK3 } \\
\text { LMJG } \\
\text { MAND }\end{array}$ & -4.8428 & 112.2156 & -32.7820 & 22.2156 & 27.9392 & -37.6249 & -0.00000051 \\
\hline 7 & $\begin{array}{l}\text { LCK3 } \\
\text { LHAZ } \\
\text { DEHR }\end{array}$ & 14.7317 & 107.3167 & -26.6095 & 17.3167 & 41.3412 & -11.8778 & -0.00000125 \\
\hline 8 & $\begin{array}{c}\text { LCK3 } \\
\text { LHAZ } \\
\text { MAND }\end{array}$ & 14.6399 & 101.2933 & -33.9151 & 11.2933 & 48.5551 & -19.2752 & -0.00000099 \\
\hline 9 & $\begin{array}{l}\text { PANT } \\
\text { DEHR } \\
\text { MAND }\end{array}$ & 27.8298 & 115.7961 & -95.2986 & 25.7961 & 123.1284 & -67.4689 & -0.00000122 \\
\hline 10 & $\begin{array}{l}\text { HYDE } \\
\text { PANT } \\
\text { LHAZ }\end{array}$ & 22.7571 & 135.0047 & -15.7791 & 45.0047 & 38.5362 & 6.9780 & -0.00000129 \\
\hline 11 & $\begin{array}{c}\text { LMJG } \\
\text { MAND } \\
\text { LHAZ }\end{array}$ & 178.5316 & 154.5262 & 6.3180 & 64.5262 & 172.2136 & 184.8496 & 0.00000071 \\
\hline 12 & $\begin{array}{l}\text { HYDE } \\
\text { LMJG } \\
\text { PANT }\end{array}$ & 6.3741 & 156.4692 & -20.9363 & 66.4692 & 27.3105 & -14.5622 & -0.00000086 \\
\hline
\end{tabular}

